\title{
The Expression of UGT46A1 Gene and Its Effect on Silkworm Feeding
}

\author{
Wenting Song ${ }^{1}\left(\mathbb{D}\right.$, Yixuan Fan ${ }^{1}$, Feifei Zhu ${ }^{1}$, Rehab Hosny Taha ${ }^{2}$ and Keping Chen ${ }^{1, *} \mathbb{C}$ \\ 1 School of Life Sciences, Jiangsu University, 301 Xuefu Road, Zhenjiang 212013, China; \\ s1064180249@163.com (W.S.); 13626169459@163.com (Y.F.); feifzhu@ujs.edu.cn (F.Z.) \\ 2 Sericulture Research Department, Plant Protection Research Institute of the Agricultural Research Center, \\ Agriculture and Land Reclamation, 42 About E1-Fad1 Mosque, E1-Sahe1, Cairo, Egypt; \\ Rehab_hosny@hotmail.com \\ * Correspondence: kpchen@ujs.edu.cn; Tel.: +86-511-8879-1923
}

check for updates

Citation: Song, W.; Fan, Y.; Zhu, F.; Taha, R.H.; Chen, K. The Expression of UGT46A1 Gene and Its Effect on Silkworm Feeding. Processes 2021, 9 , 1473. https://doi.org/10.3390/ pr9081473

Academic Editor:

Ángeles Alonso-Moraga

Received: 23 July 2021

Accepted: 20 August 2021

Published: 23 August 2021

Publisher's Note: MDPI stays neutral with regard to jurisdictional claims in published maps and institutional affiliations.

Copyright: (c) 2021 by the authors. Licensee MDPI, Basel, Switzerland. This article is an open access article distributed under the terms and conditions of the Creative Commons Attribution (CC BY) license (https:// creativecommons.org/licenses/by/ $4.0 /)$.

\begin{abstract}
The silkworm, Bombyx mori, uses a complex olfactory system to determine whether the food is edible. As an odor degrading enzyme, UDP-glycosyltransferase (UGT) participates in the degradation of odor molecules in the olfactory system of the silkworm. By sequencing the whole genome of the silkworm NB and using comparative genomics methods, we found that UGT46A1 is unique in species that eat mulberry leaves. Bioinformatics shows that its function may be related to the feeding habits of the silkworm. In this study, it was found through quantitative real-time polymerase chain reaction (qRT-PCR) that UGT46A1 was highly expressed in the heads of silkworms, which was consistent with the conjecture that UGT46A1 was involved in silkworm olfactory recognition. RNA interference (RNAi) was used to knock down the expression of UGT46A1. By observing the silkworm's tendency toward mulberry leaves and food selectivity, it was found that the silkworms that successfully knocked down the UGT46A1 gene altered their feeding habits and that their ability to find food was weakened, but they could eat more leaves of plants other than mulberry leaves. This evidence indicates that UGT46A1 may affect the silkworm's feeding by influencing the olfactory system of the silkworm.
\end{abstract}

Keywords: Bombyx mori; UGT46A1; RNA interference; feeding behavior; food selection

\section{Introduction}

Bombyx mori is a herbivorous insect and generally only eats mulberry leaves, but when they are in an extremely hungry condition, they can also feed on some plant leaves such as those from Ulmaceae, Compositae, and Urticaceae [1,2]. However, it is difficult for the leaves of other plants to provide all the nutrients required by the silkworm, and these leaves generally cannot guarantee the healthy growth and reproduction of the silkworm and may even poison the silkworm and cause it to die [1]. Silkworms can spin silk and form cocoons, which has important economic significance, but the traditional way of raising silkworms with mulberry leaves can no longer meet the needs of contemporary economic development. In order to solve the problem of consuming a lot of manpower and material resources in the process of collecting mulberry leaves, there is a need to analyze the molecular mechanism that affects the silkworm's feeding habits and to breed polyphagous silkworms.

The feeding habits of insects are very complex. They need to use the feedback information in the chemoreceptive nervous system (including smell and taste) to guide the chemotaxis, foraging, and feeding behaviors [3]. The feeding process of insects is usually summarized as host plant perception, the initiation of biting, feeding action or test biting, continuous feeding, and stopping eating [4-6]. The recognition process of molecules by insects is the first step for insects to determine whether they can ingest food. This process requires the participation of odorant-binding proteins (OBPs) $[7,8]$, chemosensory proteins 
(CSPs) $[9,10]$, sensory neuron membrane proteins (SNMPs) [11,12], olfactory receptors (ORs) $[13,14]$ and odorant degrading esterases (ODEs) $[15,16]$, and other proteins.

UDP-glycosyltransferase (UGT), an important ODE in insects, has been proven to react to a variety of plant allelochemicals $[17,18]$. UGT enzyme activity has been detected in the insect brain, olfactory tissue, fat body, midgut, and other tissues $[19,20]$. It was first demonstrated in Spodoptera littoralis that odor exposure can regulate UGT expression. UGTs catalyze the transfer of the sugar base of nucleotides to the aglycone of the acceptor molecule, which converts the acceptor molecule from hydrophobic to hydrophilic [21]. UGT40R3 and UGT46A6 were found to be specifically expressed or overexpressed in the antennae of Spodoptera littoralis, and male moths will differentially down-regulate the expression levels of these two genes under the influence of sex pheromone and plant odor. In addition, UGT46A6 also plays an important role in protecting the olfactory organs from foreign substances [22]. Huang et al. identified 42 putative UGTs in silkworms, of which 36 were expressed in different tissues [23]. This indicates that these genes are active and may have different functions. UGT [24], cytochrome P450 (P450), glutathione S-transferases (GST), and carboxylesterases (CCE) are all important detoxification enzymes in insects $[25,26]$. They can degrade toxic phytochemicals in food to resist the harm caused by food toxic ingredients to the body [27]. There is an important correlation between the number of P450, CCE, and GST genes and eating preference [28]. Omnivores and herbivores have more detoxification genes, while species that eat simpler tissues such as sap, nectar, and blood have relatively fewer detoxification genes [29]. All of this evidence indicates that UGT may affect the olfactory function and feeding choices of insects. We sequenced the whole genome of NB, compared it with the gene families of other species that did not eat mulberry leaves, and combined with the Gene Ontology (GO) and Kyoto Encyclopedia of Genes and Genomes (KEGG) enrichment analysis to find that UGT46A1 ranked highest, which may affect the feeding habits of silkworm.

In this study, we performed cloning and expression, bioinformatics analysis, and spatiotemporal expression of the UGT46A1 gene in the silkworm and knocked down the expression of UGT46A1 by RNA interference (RNAi) technology to study the effect on silkworm feeding behavior. These results will provide insight for the future study of the silkworm olfactory system and silkworm feeding habits and lay a foundation for the breeding of polyphagous silkworms.

\section{Materials and Methods}

\subsection{Animal Models}

The B. mori strains NB were obtained from the School of Life Sciences of Jiangsu University (Zhenjiang, China) and were resistant to the Bombyx mori Nucleopolyhedrovirus. The larvae were reared on fresh mulberry under a constant $14 \mathrm{~h}$ light $/ 10 \mathrm{~h}$ dark photoperiod at $25{ }^{\circ} \mathrm{C}$ and $75 \%$ relative humidity. Egg, larvae at the first day of each instar, pupa, and moth were collected for gene expression analysis. The tissues of the head, midgut, fat body, Malpighian tubules, and silk glands were dissected on the third day of fifth-instar larvae. A total of five independent tissues or dissected individuals were pooled and homogenized as one sample. All samples were frozen using liquid nitrogen and stored at $-80{ }^{\circ} \mathrm{C}$ for RNA purification.

\subsection{RNA Purification and $c D N A$ Synthesis}

Total RNA was separately extracted using TRIzol ${ }^{\circledR}$ reagent (Invitrogen, Carlsbad, CA, USA) according to the manufacturer's instructions. RNA integrity was checked by $1.0 \%$ agarose gel electrophoresis. A NanoPhotometer ${ }^{\circledR}$ ultraviolet spectrophotometer (IMPLEN, GER) was used to detect RNA purity, and a Qubit ${ }^{\circledR} 2.0$ fluorescence spectrophotometer (Thermo Scientific, Wilmington, DE, USA) was used to detect RNA concentration. The first strand of cDNA was synthesized using a HiScript Q RT SuperMix for a qPCR Kit (Vazyme, Nanjing, China), following the manufacturer's instructions. 


\subsection{Cloning, Expression, and Bioinformatics Analysis of UGT46A1}

The de novo sequencing and assembling of the genome of NB were performed through the Pacbio third-generation sequencing platform, Illumina second-generation sequencing platform, and Hi-C technology. The sequencing work was completed by Novogene Co., Ltd. (Beijing, China). The genome data has been uploaded to the National Center for Biotechnology Information (NCBI) database (Registration number: PRJNA721561). We used NB, Japanese silkworm p50T, and Bombyx mandarina that eat mulberry leaves as the foreground branches, and Pieris rapae, Antheraea yamamai, Spodoptera frugiperda, Helicoverpa armigera, Danaus plexippus, and Plutella xylostella that do not eat mulberry leaves as background branches to perform gene family cluster analysis and Venn analysis. The gene information of each species was obtained from NCBI (https:/ /www.ncbi.nlm.nih.gov/, accessed on 20 March 2020), GigaDB (http:/ /gigadb.org/, accessed on 20 March 2020), and SilkBase (http:/ / silkbase.ab.a.u-tokyo.ac.jp/cgi-bin/index.cgi, accessed on 20 March 2020). Gene families shared by the foreground branch species and not in the background branch were found. The GO and KEGG enrichment analysis of these gene families revealed that UGT46A1 was involved in multiple pathways in both GO and KEGG with high enrichment levels (Supplementary Figures S1 and S2), including many pathways that may be related to feeding habits (Supplementary Tables S1 and S2). Therefore, in order to verify whether UGT46A1 has an effect on silkworms' feeding habits, we cloned and expressed UGT46A1 in the prokaryotic system. The Primers were designed according to the cDNA sequence of the UGT46A1 gene (GenBank number: NM_001257053); forward primer: 5'-CCCAAGCTTATGCGTGCCGTGCCATT-3'; and reverse primer: 5'CCCTCGAGGTGTAATTTCTCTTTAGCAGTGACACTACCGC- $3^{\prime}$. The cDNA obtained above was used as a template to perform Polymerase Chain Reaction (PCR) amplification of the complete open reading frame (ORF) of the UGT46A1 gene. Prokaryotic expression was performed after the correct sequencing by Sangon Biotech Co., Ltd. (Shanghai, China), and the expression of UGT46A1 was verified by SDS-PAGE electrophoresis and Western blot. The full-length amino acid sequence of the silkworm UGT46A1 was used to perform a homology search in the NCBI database, the DNAMAN software was used to analyze the similarity of the amino acid sequences of UGT46A1 homologous proteins from different species, the Clustal X 1.83 software was used to perform the screening of the amino acid sequences and the alignment of multiple sequences, and the maximum likelihood method of MEGA 7.0 [30] software was used to construct a phylogenetic tree.

\subsection{Quantitative Real-Time Polymerase Chain Reaction ( $q R T-P C R$ )}

The Primers were designed based on the UGT46A1 gene (GenBank number: NM_001257053) sequence of the silkworm using online Primer3 software (http:/ / primer3 .ut.ee/, accessed on 20 March 2021). The B. mori cytoplasmic actin A3 gene (GenBank number: NM_001126254) was used as an internal control. All primer information is listed in Table 1. The qRT-PCR reactions were performed on a LightCycler ${ }^{\circledR} 480$ Real-Time PCR system (Roche Diagnostics, Indianapolis, IN, USA) in a total reaction volume of $20 \mu \mathrm{L}$, containing $10 \mu \mathrm{L}$ of $2 \times$ AceQ Universal SYBR qPCR Master Mix (Vazyme, Nanjing, China), $0.4 \mu \mathrm{L}$ of each primer $(10 \mu \mathrm{M}), 4 \mu \mathrm{L}$ of cDNA, and $5.2 \mu \mathrm{L}$ of $\mathrm{ddH}_{2} \mathrm{O}$. The qRT-PCR was performed using the following program: $95^{\circ} \mathrm{C}$ for $5 \mathrm{~min}$, followed by 40 cycles of $95^{\circ} \mathrm{C}$ for $10 \mathrm{~s}$, and then annealed at $60^{\circ} \mathrm{C}$ for $30 \mathrm{~s}$, one cycle of $95^{\circ} \mathrm{C}$ for $15 \mathrm{~s}, 60^{\circ} \mathrm{C}$ for $60 \mathrm{~s}$, and $95^{\circ} \mathrm{C}$ for $15 \mathrm{~s}$. The relative transcript abundances were calculated using the $2^{-\Delta \Delta C T}$ method [31]. All of the experiments were repeated in triplicates. 
Table 1. Primers information for qRT-PCR.

\begin{tabular}{ccc}
\hline Genes & Primer Names & Sequences \\
\hline \multirow{2}{*}{ UGT46A1 } & UGT46A1-F & GCGTGCCGTGCCATTTCATTAC \\
& UGT46A1-R & CATCGTGTCCTCTCTCAGCCAATC \\
\multirow{2}{*}{ Actin A3 } & Actin A3-F & AACGGAATCCACGAAACCAC \\
& Actin A3-R & ACAATACGGTGTTGGCGTAC \\
\hline
\end{tabular}

\subsection{Double Strand RNA Synthesis and Injection}

The online website CRISPRdirect (http:/ / crispr.dbcls.jp/, accessed on 12 April 2021) was used to design multiple dsRNAs, and 3 dsRNAs were selected according to the dsRNA design principles (Table 2). The dsRNA was synthesized by Sangon Biotech Co., Ltd. (Shanghai, China). The silkworms with similar growth conditions were selected and injected on the first day of fifth instar. The silkworms were starved for $1 \mathrm{~h}$ and placed on ice for $1 \mathrm{~min}$ before injection. Each silkworm was injected with $10 \mu \mathrm{L}$ of UGT46A1 dsRNA $\left(500 \mathrm{ng} \cdot \mu \mathrm{L}^{-1}\right)$ with microsyringes, and $10 \mu \mathrm{L}$ of the negative control interference fragment $\left(500 \mathrm{ng} \cdot \mu \mathrm{L}^{-1}\right)$ was injected in the same way for the control group. A total of 30 silkworms were injected in each group. In order to not damage the silkworm tissues, the injection site was chosen to be the side of the third internode membrane from the front of the silkworm's tail. At 24, 48, 72, 96, and $120 \mathrm{~h}$ after injection, five silkworms were randomly selected from each group for dissection and then mixed. At $48 \mathrm{~h}$ after the injection of dsRNA, the interference effect of the three dsRNAs on the expression of UGT46A1 was detected, the best interference dsRNA fragment was determined, and the relative expression level of the silkworm UGT46A1 gene at different times after the injection of the best interference fragment was detected by qRT-PCR.

Table 2. DsRNA sequence information.

\begin{tabular}{cccc}
\hline Name & Target Location & Sense Strand & Antisense Strand \\
\hline dsRNA-1 & UGT46A1-337 & GCAGACUUCGCUUUAGAUATT & UAUCUAAAGCGAAGUCUGCTT \\
dsRNA-2 & UGT46A1-987 & GCAGAGAGUUAUCUGGAAATT & UUUCCAGAUAACUCUCUGCTT \\
dsRNA-3 & UGT46A1-1550 & GCGGUAGUGUCACUGCUAATT & UUAGCAGUGACACUACCGCTT \\
Negative control & control & UUCUCCGAACGUGUCACGUTT & ACGUGACACGUUCGGAGAATT \\
\hline
\end{tabular}

\subsection{Determination of Feeding Behavior}

In order to detect the effect of UGT46A1 on the feeding of silkworm, the best interference dsRNA and negative control were chosen to inject 50 silkworms in each group. After the injection, 50 silkworms from the experimental group (EG), 50 from the control group (CG), and 50 from the wild-type (WT) were starved for $24 \mathrm{~h}$. The feeding behavior was measured in a transparent plastic box with a lid sized at $30 \mathrm{~cm} \times 24 \mathrm{~cm} \times 4.5 \mathrm{~cm}$ after $24 \mathrm{~h}$ of fast. Mulberry and gardenia leaves were cut into squares of the same size, and four leaves of each variety were placed in each group, with three groups placed in total. Four EG, CG, and WT silkworms were placed on the other side, $20 \mathrm{~cm}$ away from the leaves, and the location of the larvae was recorded every $15 \mathrm{~min}$. In order to avoid the accidental crawling of silkworms, the experiment was carried out for 10 groups at the same time. In addition, in order to verify the effect of UGT46A1 on the food selectivity of the silkworms, we separately fed 10 EG and 10 CG silkworms only gardenia leaves to observe the feeding situation of the silkworms.

\section{Results}

\subsection{The Cloning, Expression, and Bioinformatics Analysis of UGT46A1}

We used PCR to amplify a complete ORF sequence of $1061 \mathrm{bp}$ (with the addition of protected bases) (Figure 1A). The results of the SDS-PAGE electrophoresis and Western blot showed that the UGT46A1 protein was successfully expressed and the protein size was 
about $63 \mathrm{kD}$ (Figure 1B). The DNAMAN software was used to carry out multiple sequence comparisons, and it was found that the amino acid sequence similarity of BmUGT46A1 (NP_001243982), BmUGT46A2 precursor (NP_001243972), and BmUGT46A1 homologous protein in Bombyx mandarina (XP_028030281), Manduca sexta (KAG6449394), Helicoverpa armigera (XP_021186279), and Spodoptera litura (XP_022814630) was 78.18\%, 78.56\%, 68.56\%, $65.28 \%$, and $65.28 \%$, respectively (Figure 2 ). In order to further analyze the characteristics of the silkworm UGT46A1, a phylogenetic tree was constructed for the silkworm UGT46A1 and its homologous sequences. The results showed that the BmUGT46A1, BmUGT46A2 precursor, and 2-hydroxyacylsphingosine 1-beta-galactosyltransferase-like isoform X1 of the Bombyx mandarian are gathered on one branch (Figure 3).

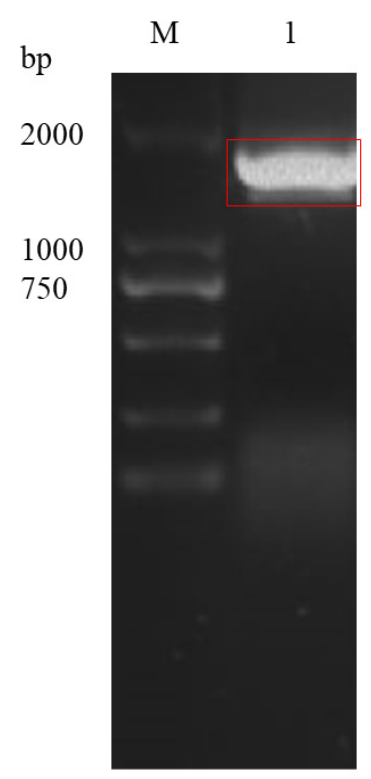

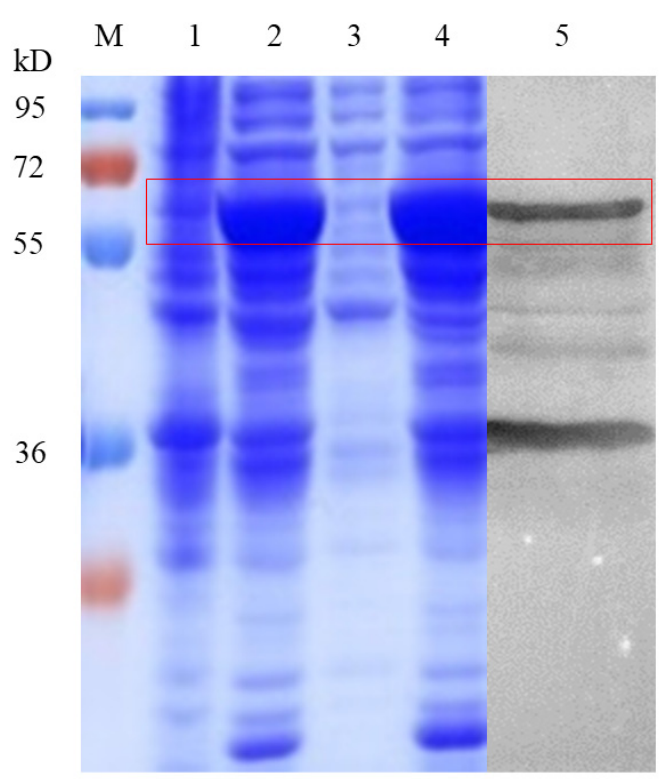

Figure 1. Cloning and expression of the UGT46A1 gene. (A) Electrophoretogram of the UGT46A1 gene by PCR amplification. M: DNA marker; 1: PCR product of UGT46A1 gene; the strip in the red box is UGT46A1. (B) The prokaryotic expression of the UGT46A1 protein was detected by SDS-PAGE and Western blot with His tag. M: Protein marker; 1: Empty vector; 2: Total bacterial lysate induced by IPTG ( $4 \mathrm{~h}$ after induction with $0.5 \mathrm{mM}$ IPTG, $37^{\circ} \mathrm{C}$ ); 3: supernatant after the ultrasonic breakdown of total lysate; 4: precipitate after ultrasonic breakdown; 5: Western blot exposure image of the UGT46A1 protein. The strip in the red box is the UGT46A1 protein.

\subsection{The Temporal Expression of UGT46A1 in B. mori}

The expression of UGT46A1 in different growth states of silkworms and the five tissues of head, midgut, fat body, Malpighian tubules, and silk gland on the third day of the fifth instar were analyzed by qRT-PCR. The results showed that the silkworm UGT46A1 gene was expressed at a higher level in the head and fat body and at a lower level in the Malpighian tubules and silk glands (Figure 4A). In addition, the expression level of the BmUGT46A1 gene in the moth stage was significantly higher than that in other stages (Figure 4B). 
UGT 46A1_Bombyx mori UGT 46A2_precursor_Bombyx_mori Bombyx_mandarin Manduca_sexta

Helicoverpa_armigera

Spodoptera $\bar{l}$ itura

Consensus

UGT 46A1 Bombyx mori

UGT 46A2 precursor Bombyx mor

Bombyx mandarina

Manduca sexta

Helicoverpa armigera

Spodoptera_īitura

Consensus

UGT 46A1_Bombyx_mori

UGT 46A2_precursor_Bombyx_mor

Bombyx_mandarina

Manduca_sexta

Helicoverpa_armigera

Spodoptera_ilitura

Consensus

UGT 46A1 Bombyx mori

UGT $46 \mathrm{~A} 2$ precursor Bombyx mor

Bombyx_mandarina

Manduca_sext

Helicoverpa armigera

Consensus

UGT 46A1_Bombyx mori

UGT 46 A2 precursor Bombyx mor

Manduca sexta

Helicoverpa armigera

Spodoptera $\bar{l}$ itura

Consensus

UGT 46A1 Bombyx mor

UGT 4 6A2 precursor Bombyx mor

Bombyx mandarina

Manduca sexta

Helicoverpa_armigera

Spodoptera_litur
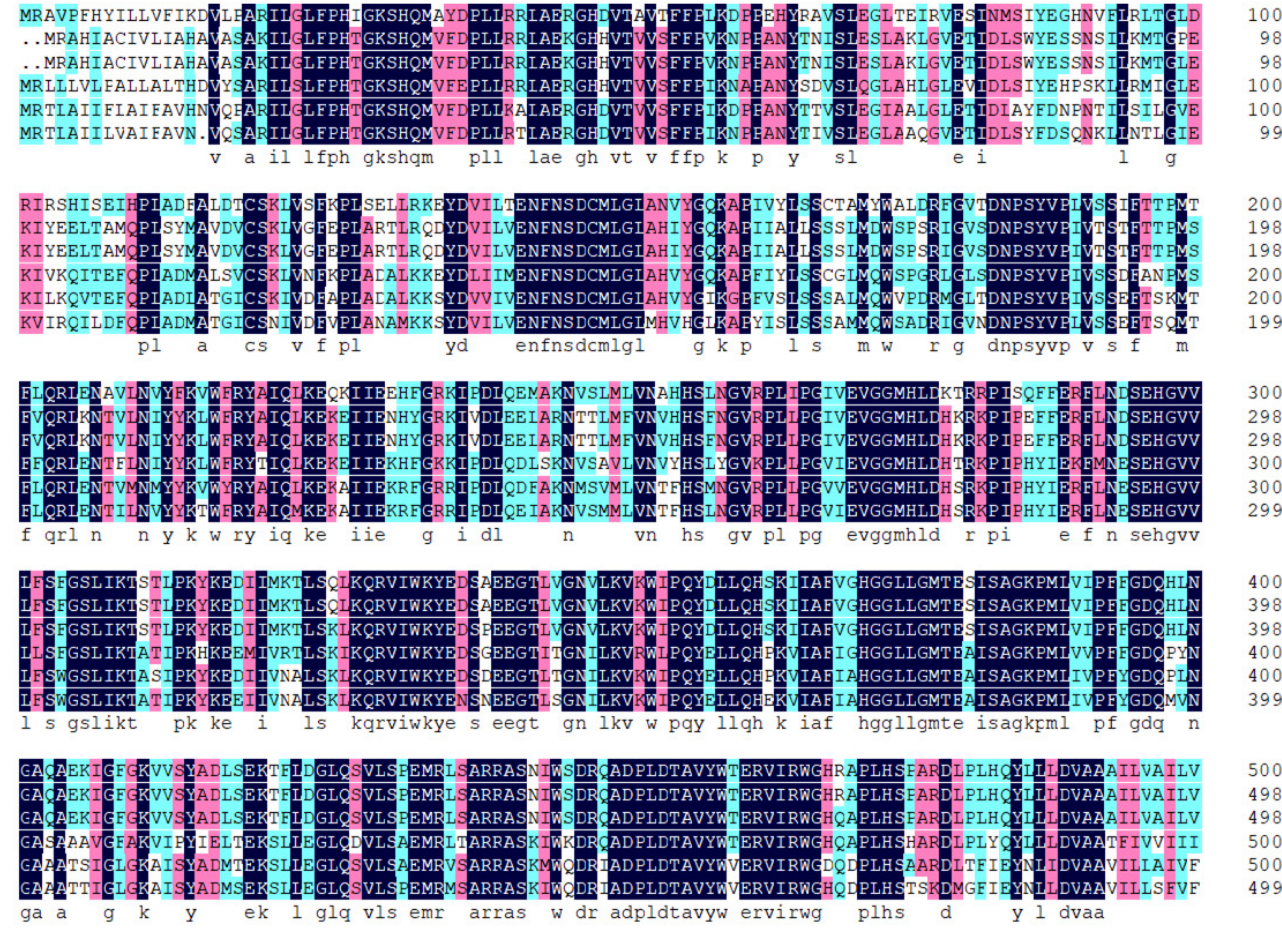

500
498
498
500
500
499

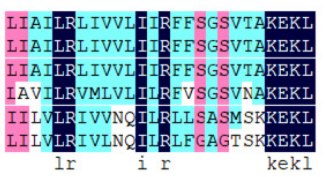

98

100
99

\section{8}

Figure 2. Alignment of the amino acid sequence similarity of BmUGT46A1 (NP_001243982), BmUGT46A2 precursor (NP_001243972), and BmUGT46A1 homologous protein in Bombyx mandarina (XP_028030281), Manduca sexta (KAG6449394), Helicoverpa armigera (XP_021186279), and Spodoptera litura (XP_022814630).

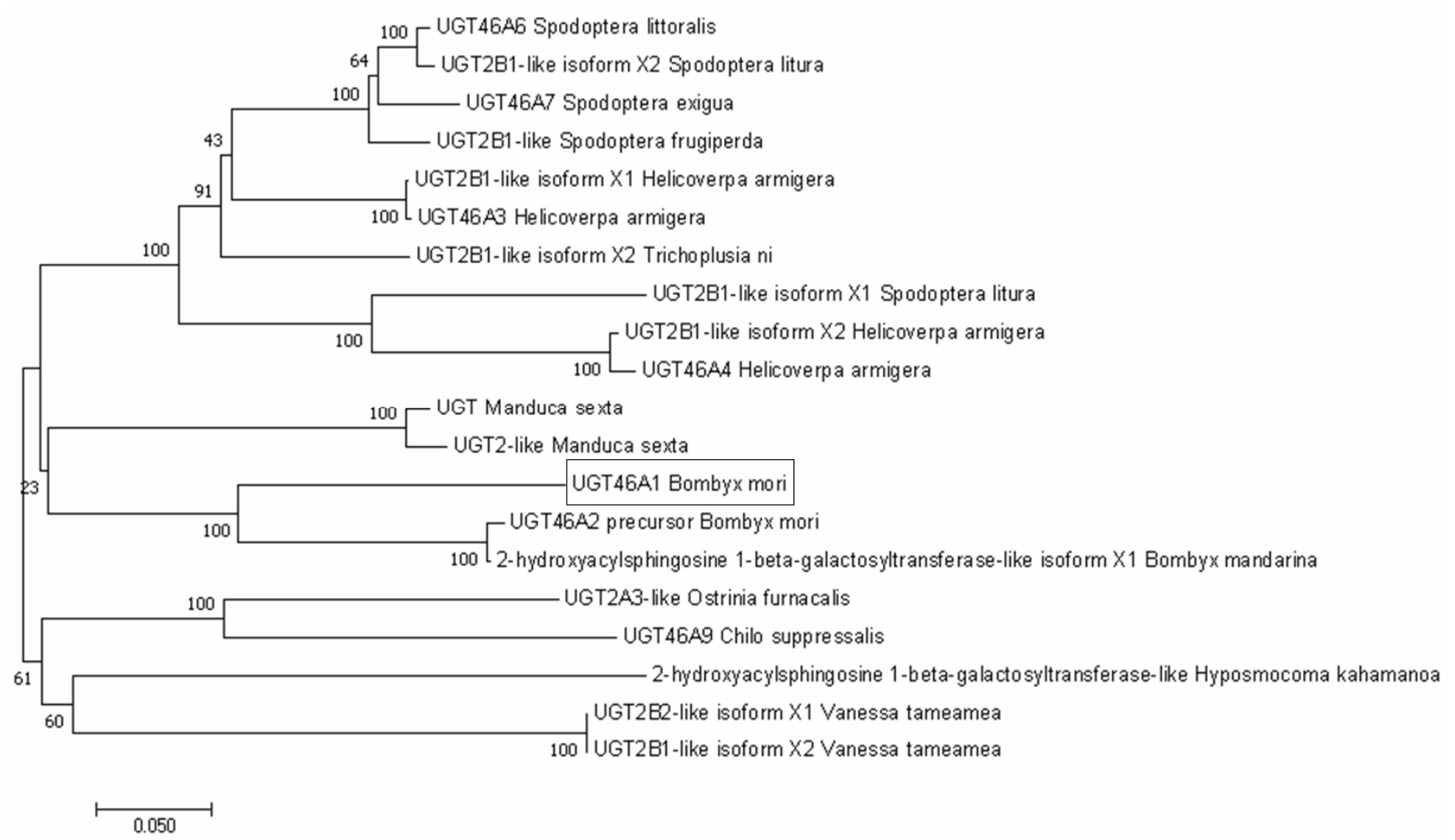

Figure 3. Phylogenetic tree of UGT46A1 and other homologous proteins. Neighbor-Joining tree was produced by MEGA7. One thousand bootstraps were performed for checking the reproducibility of the result. 


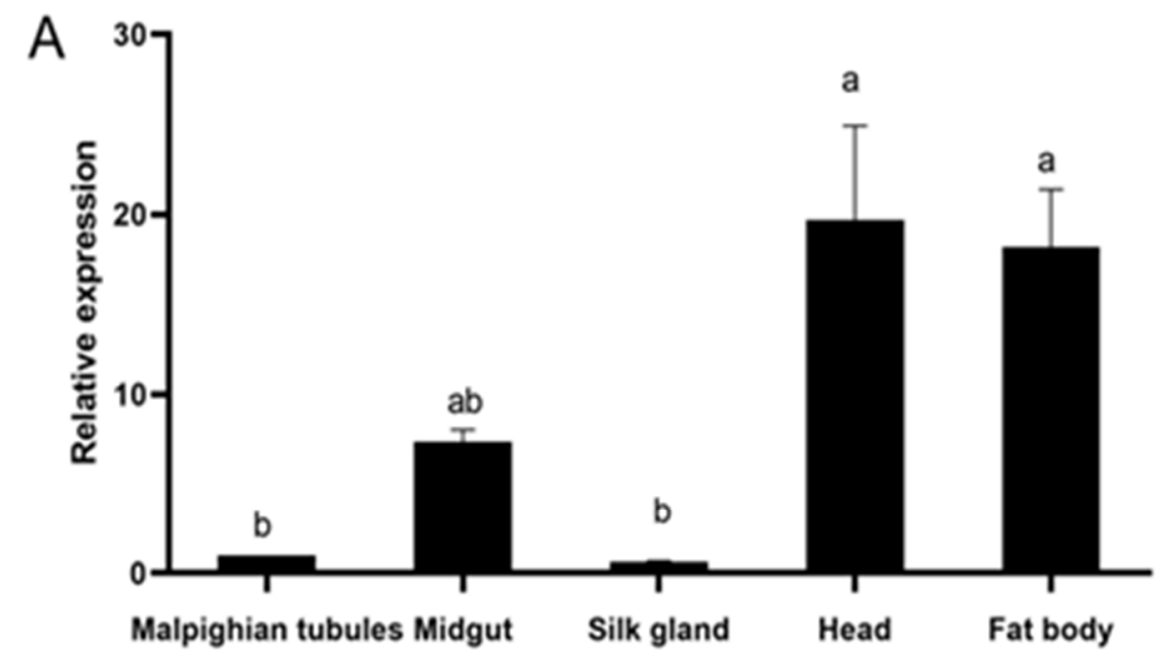

Different tissues

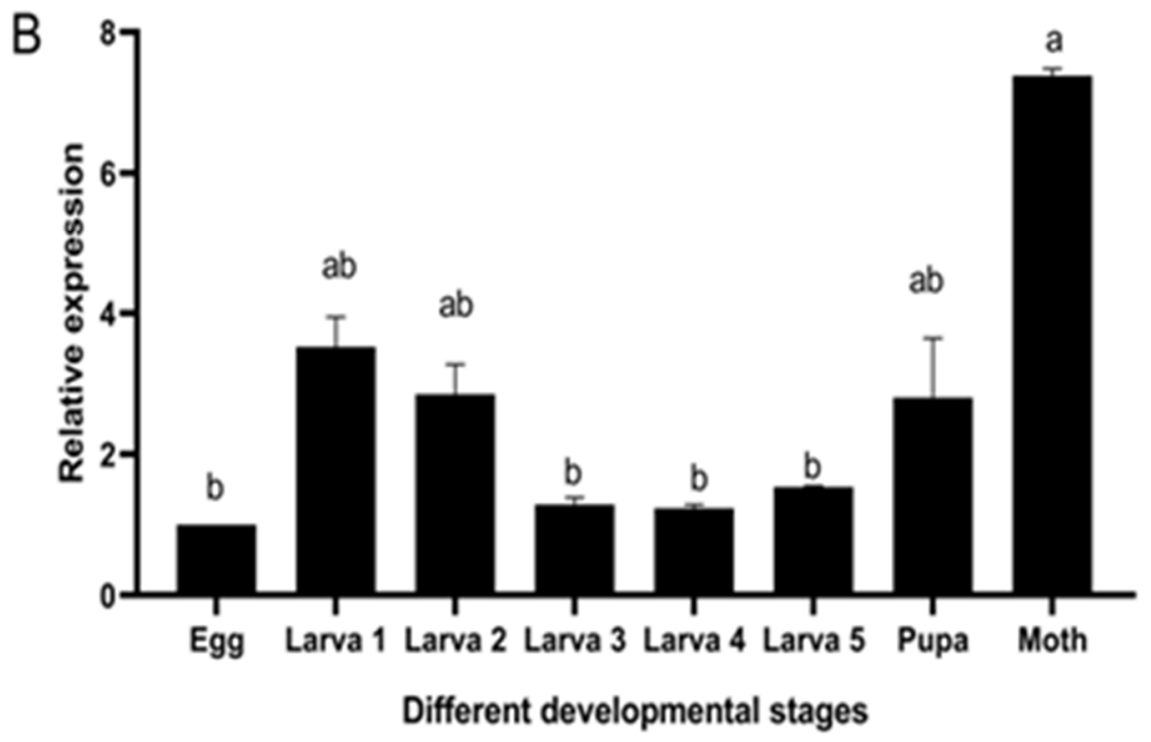

Figure 4. Relative mRNA level of the BmUGT46A1 gene in different tissues and different developmental stages. (A) Relative mRNA levels in the head, midgut, fat body, Malpighian tubules, and silk gland. The relative expression of UGT46A1 in the Malpighian tubules group (quantity was 1) was the control group. (B) The relative mRNA levels of UGT46A1 in whole silkworms at different developmental stages. The relative expression of UGT46A1 in the egg group (quantity was 1) was the control group. The expression levels were examined using quantitative real-time PCR. The gene actin $A 3$ was used as the internal control. The data shown were the mean $\pm \operatorname{SD}(n=3)$. Different letters indicate statistical differences. The same letters in the figure indicate that the difference was not significant; different letters indicate that the difference was significant (ANOVA, Tukey test, $p<0.05$ ).

\subsection{Knockdown Effect of dsRNA on UGT46A1 in B. mori}

In order to ensure the knockdown of UGT46A1 expression by RNAi, we designed three dsRNAs and respectively detected the relative expressional level of UGT46A1 at $48 \mathrm{~h}$ after injection. Five silkworms in each group were randomly selected for dissection and then mixed, and qRT-PCR was performed. The results showed that dsRNA-1 and dsRNA-2 had no interference effect on the UGT46A1 gene expression of silkworm, and only dsRNA-3 interfered successfully. Due to the different target positions of small dsRNA, RNA activation (RNAa) will occur. Like dsRNA-1 and dsRNA-2, dsRNA that can induce RNAa 
and target the non-coding regions of genes was called small activating RNA (saRNA) [32]. A total of $48 \mathrm{~h}$ after the injection of dsRNA-3, the expression of the UGT46A1 gene decreased to $52.4 \%$ (Figure 5). In subsequent experiments, the dsRNA-3 injection of silkworm samples was used to analyze the feeding behavior of silkworms.

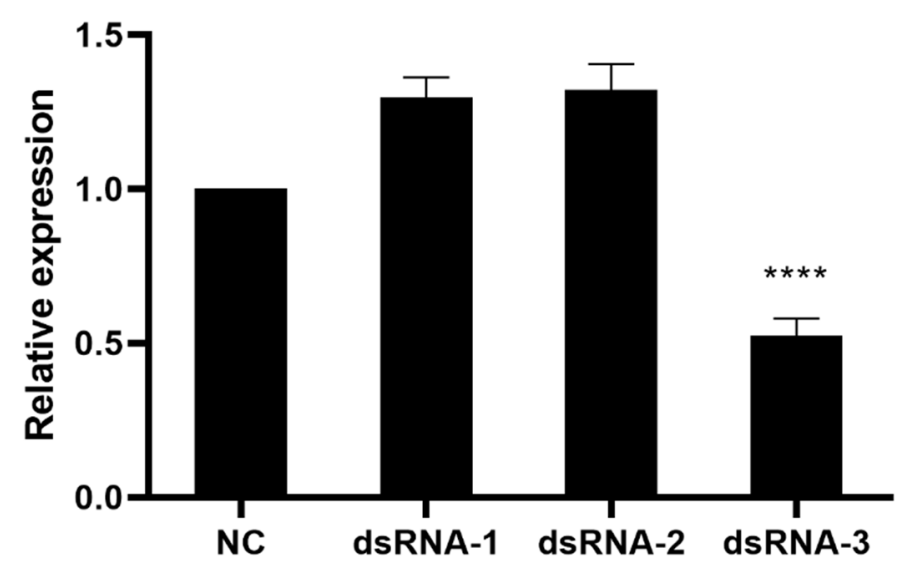

Figure 5. The relative expression level of the UGT46A1 gene in the experimental group relative to the negative control group after $48 \mathrm{~h}$ of the injection of different dsRNA fragments. NC: Negative control. Actin A3 was the internal control. The expression of negative interference fragments injected (quantity was 1) was used as the NC group. The expression of other interference fragments injected was relative compared with the control group. ${ }^{* * * *}$ indicates statistically significant $(t$-test, $p<0.0001)$. All data were presented as the mean $\pm \mathrm{SD}(\mathrm{n}=3)$.

\subsection{Effective Time of RNA Interference}

The total RNA of five silkworms was extracted separately at 24, 48, 72,96, and $120 \mathrm{~h}$ after the injection of dsRNA-3, and the relative expression of the UGT46A1 gene was detected by qRT-PCR. The results showed that the down-regulation effect of the UGT46A1 gene decreased with time, the down-regulation effect reached the highest at $24 \mathrm{~h}$ after injection, and the interference effect was lost at $120 \mathrm{~h}$ (Figure 6).

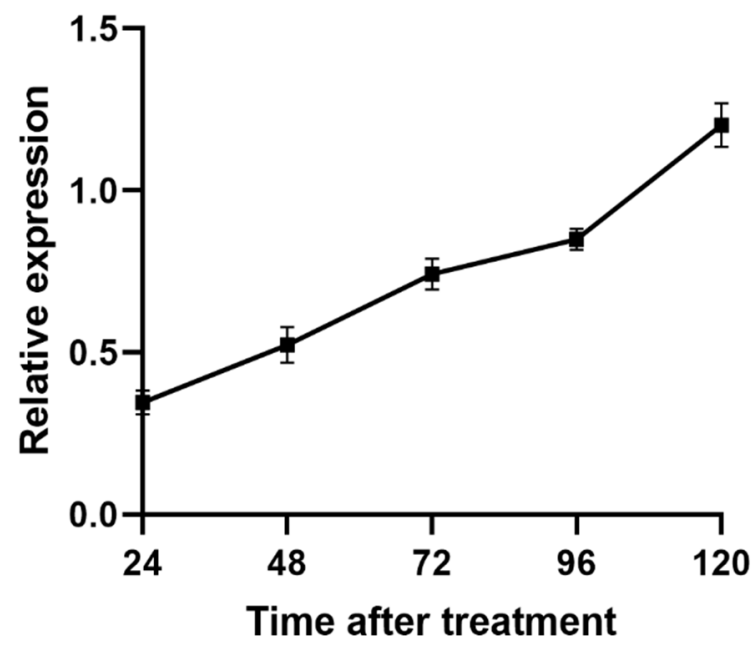

Figure 6. Interference effect of silkworm UGT46A1 at different times after dsRNA-3 injection. The expression of the injected negative interference fragment (quantitative value is 1 ) was used as the control group. The expression of the injected interference fragments was compared with the control group. All data were presented as the mean $\pm \operatorname{SD}(n=3)$. 


\subsection{Results of Feeding Behavior Measurement}

We randomly selected four EG, CG, and WT silkworms respectively to test the degree of attraction of silkworms to the odor of mulberry leaves and gardenia leaves. At $30 \mathrm{~min}$, both the CG and the WT had an obvious tendency to crawl to the leaves. Three silkworms from the CG crawled forward, and one from the WT crawled forward. The EG remained in place. At $60 \mathrm{~min}$, two CG silkworms and one WT silkworm started to eat and preferentially took mulberry leaves. The EG remained in place. At $90 \mathrm{~min}$, one silkworm in the EG crawled forward, and at $130 \mathrm{~min}$, only one silkworm in the experimental group could eat mulberry leaves (Figure 7). The time the CG and WT silkworms began to crawl on the mulberry leaves and the time they started to eat mulberry leaves were earlier than the EG silkworms.

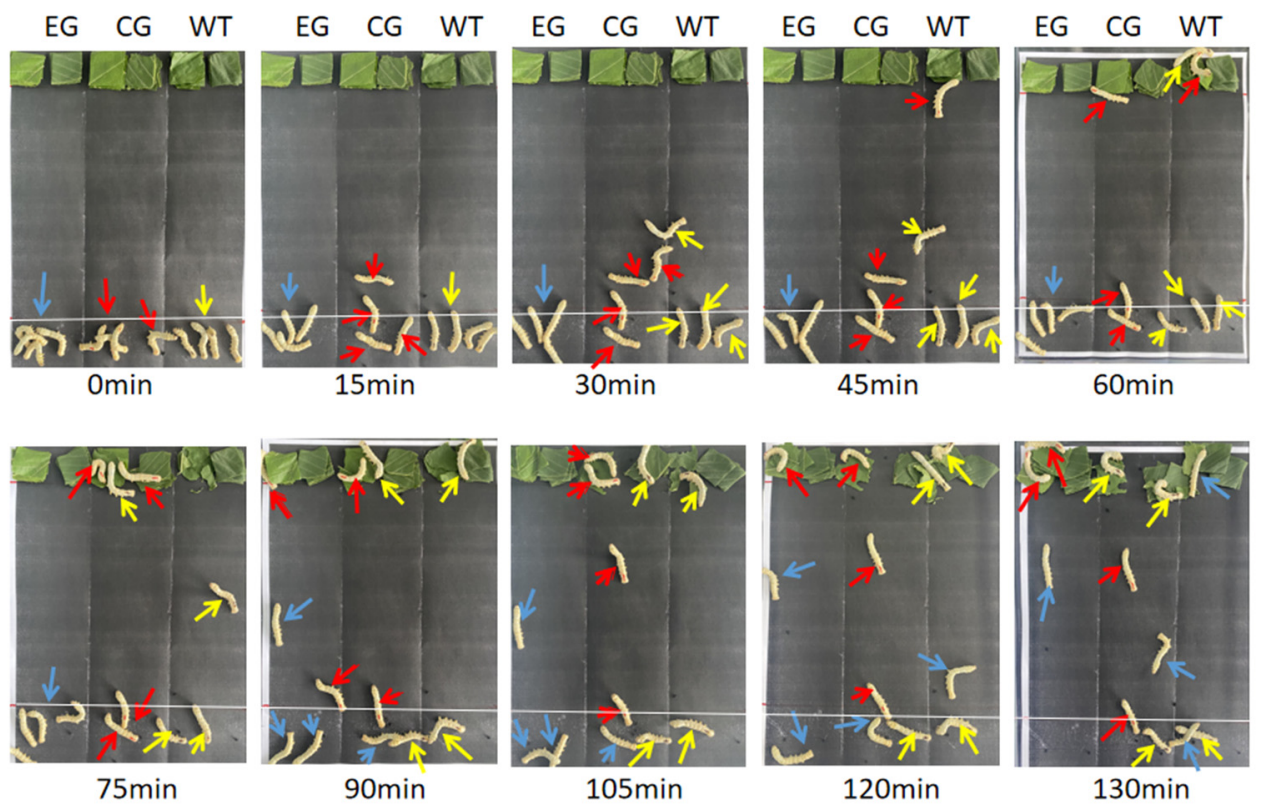

Figure 7. The crawling trajectory of Bombyx mori after 24 injections of dsRNA. EG: experimental group; CG: control group; WT: wild type. The silkworms pointed out by the blue arrows are the experimental group, the silkworms pointed out by the red arrows are the control group, and the silkworms pointed out by the yellow arrows are the wild type. The left side of each group of leaves is mulberry leaves, and the right side is gardenia leaves.

\subsection{Determination of Food Selectivity of Silkworm}

In order to further study the effect of UGT46A1 on silkworm feeding, we placed 10 EG and 10 CG silkworms in a closed environment with only gardenia leaves. At $15 \mathrm{~min}$, it was found that four silkworms in the EG were actively eating gardenia leaves and eating faster. One silkworm in the CG was eating gardenia leaves slowly. At $20 \mathrm{~min}$, the CG had stopped eating. The silkworms in the EG stopped eating at $30 \mathrm{~min}$. Finally, the gardenia leaves eaten by the silkworms in the EG were significantly larger than those eaten by the CG silkworms (Figure 8). 
CG
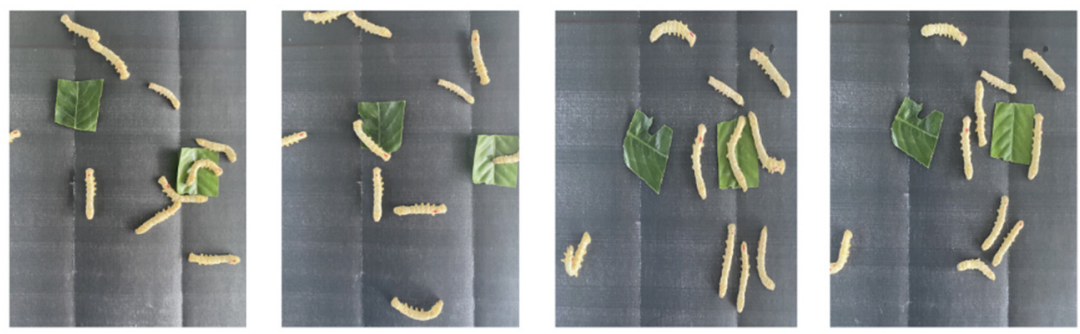

$E G$

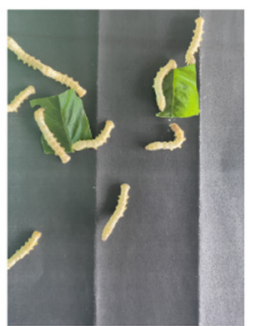

Omin

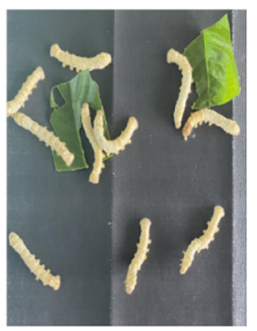

$10 \mathrm{~min}$

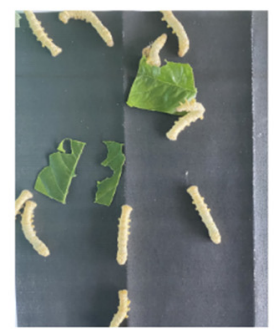

$20 \mathrm{~min}$

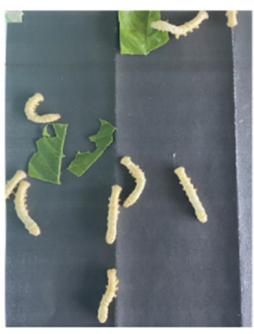

$30 \mathrm{~min}$

Figure 8. Bombyx mori after the injection of dsRNA and starving for $24 \mathrm{~h}$, fed on gardenia leaves within $30 \mathrm{~min}$. EG: experimental group; CG: control group.

\section{Discussion}

The mechanism by which the silkworm chooses mulberry leaves for food at the molecular level is not clear. Although it is reported that the choice of insect feeding is to use the chemical sensations related to taste and smell to ingest food with proper nutritional balance and to avoid bitterness and toxic substances [33], the complete genetic mechanism that affects silkworm feeding has not yet been established. The amino acid sequence comparison of the homologous proteins of the silkworm UGT46A1 showed that BmUGT46A1 is similar to the UGT protein of different species. It is speculated that UGT46A1 belongs to the UGT family and may have detoxification and odor degradation effects. The evolution analysis showed that the UGT46A1 protein of $B$. mori is closely related to the UGTs of the Bombyx mandarina, Manduca sexta, Helicoverpa armiger, Spodoptera frugiperda, Spodoptera littoralis, and Spodoptera litura species. UGT in Helicoverpa armigera was reported to be related to metabolic detoxification [34] and pheromone deactivation [35]. UGT was reported in Spodoptera litura to be associated with the insecticide response [36]. However, the relationship between UGT and feeding has not been studied in the silkworm and its near-source species. In this study, it was found that UGT46A1 was highly expressed in the head and fat body tissues of silkworms. A variety of sensory-related proteins related to olfactory behavior and chemical stimulation have been identified in the head of the silkworm [37], and the metabolites in the head may be involved in environmental information processing, signal transduction, carbohydrate metabolism, sensory activity, and other eating habit related processes [38]. The fat body is the factory of protein synthesis in the silkworm body [39,40], which can store nutrients [41], detoxify [42] and provide various biosynthetic metabolites for life cycle activities [40]. This indicated that UGT46A1 may be related to the silkworm's feeding habits, growth, and detoxification. The BmUGT46A1 gene was highly expressed in the moth stage. During this period, female moths need to release sex pheromones to attract male moths to reproduce $[43,44]$. It is speculated that UGT46A1 may be involved in the odor recognition process of the moth sex pheromone. The knockdown of UGT46A1 expression hindered the silkworm's ability to find food and allowed the silkworm to eat more food, with the exception of mulberry leaves. According to reports, UGT plays an important role in terminating various odor signals [45]. The decrease of UGT46A1 expression may limit the silkworm's ability to recognize odors so that the silkworm cannot accurately determine the location of food in time and weaken the silkworm's feeding ability. Some researchers believe that the detoxification enzyme family is related to the range of host food [29,46]. As a detoxification enzyme, the reduction of UGT46A1 expression may 
also reduce the olfactory sensitivity of the silkworm, which affects the silkworm's choice of food. At present, there are very few studies on the genetic factors affecting silkworm feeding on mulberry leaves. The volatile substance cis-jasmone in mulberry leaves can specifically attract silkworm larvae. As a specific receptor for cis-jasmone, BmOR56 is a key gene for silkworm larvae to be attracted to mulberry leaves. BmOR2 can increase the sensitivity of BmOR56 to cis-jasmone [47]. Gustatory receptor 66 (GR66) encodes a putative bitter gustatory receptor (GR), and silkworm larvae that knock out this gene can eat fruits and food crop seeds [48]. As a gustatory receptor and chemical sensor, $B m G r 6$ can regulate intestinal movement, physiological conditions, and the feeding behavior of larvae [49]. In addition, general odorant binding proteins (GOBPs) and pheromone binding proteins (PBPs) are important members of the OBP family [50]. GOBP participates in the stimulus reception of low specificity odorous molecules and is of great significance in foraging and courtship [51]. BmPBP can bind OR1 and OR3 and respond to pheromones [52]. OR19 and OR30 may specifically mediate the olfactory response of female silkworms [53]. These genetic factors that affect the feeding habits of the B. mori are concentrated in the olfactory and taste system. The field of research on silkworms' feeding habits only opens up a small area, and future research should be focused on the olfactory and taste systems.

\section{Conclusions}

It was found by qRT-PCR that UGT46A1 had the highest expression in the head and moth stages, and by RNAi, it was found that the silkworm with the UGT46A1 expression level knocked down had a weakened feeding ability and could eat more plant leaves, except for mulberry leaves, in a short time. It is speculated that UGT46A1 can affect the silkworm olfactory system and reduce the silkworm olfactory sensitivity. These findings provide new information for the study of silkworms' feeding habits.

Supplementary Materials: The following are available online at https:/ /www.mdpi.com/article/ 10.3390/pr9081473/s1, Figure S1: Results of GO enrichment analysis. Figure S2: Results of KEGG analysis. Table S1: Genes included in GO enrichment results. Table S2: Genes included in KEGG analysis results.

Author Contributions: W.S. and K.C. conceived the study; W.S. determined the methodology; W.S. and Y.F. performed the experiments; the data was curated by W.S.; W.S. wrote the original draft; the draft was reviewed and edited by W.S., K.C., R.H.T., and F.Z. All authors have read and agreed to the published version of the manuscript.

Funding: This work was supported by the National Natural Science Foundation of China (No. 31861143051, 31872425, and 31702186). We also acknowledge the financial support from the Academy of Scientific Research and Technology in Egypt.

Institutional Review Board Statement: Not applicable.

Informed Consent Statement: Not applicable.

Acknowledgments: We would like to thank Beijing Novogene Technology Co., LTD. for its assistance in genome sequencing, assembly, annotation, and technical support for this article.

Conflicts of Interest: The authors declare no conflict of interest.

\section{References}

1. Fraenkel, G.S. The raison d'tre of secondary plant substances; these odd chemicals arose as a means of protecting plants from insects and now guide insects to food. Science 1959, 129, 1466. [CrossRef]

2. Ishikawa, S.; Hirao, T.; Arai, N. Chemosensory basis of hostplant selection in the silkworm. Entomol. Exp. Appl. 2011, 12, 544-554. [CrossRef]

3. Zhang, H.J.; Anderson, A.R.; Trowell, S.C.; Luo, A.R.; Xiang, Z.H.; Xia, Q.Y. Topological and Functional Characterization of an Insect Gustatory Receptor. PLoS ONE 2011, 6, e24111.

4. Wilde, J. Host plant selection in the colorado beetle larva. Entomol. Exp. Appl. 2011, 1, 14-22. [CrossRef]

5. Devitt, B.D.; Smith, J. Morphology and fine structure of mouthpart sensilla in the dark-sided cutworm Euxoa messoria (Harris) (Lepidoptera: Noctuidae). Int. J. Insect Morphol. Embryol. 1982, 11, 255-270. [CrossRef] 
6. Hsiao, T.H. Chemical basis of host selection and plant resistance in oligophagous insects. Entomol. Exp. Appl. 2011, 12, 777-788. [CrossRef]

7. Yoshizawa, Y.; Sato, R.; Tsuchihara, K.; Ozaki, K.; Mita, K.; Asaoka, K.; Taniai, K. Ligand carrier protein genes expressed in larval chemosensory organs of Bombyx mori. Insect Biochem. Mol. 2011, 41, 545-562. [CrossRef] [PubMed]

8. Gong, D.P.; Zhang, H.J.; Ping, Z.; Xia, Q.Y.; Xiang, Z.H. The Odorant Binding Protein Gene Family from the Genome of Silkworm, Bombyx mori. BMC Genom. 2009, 10, 332. [CrossRef]

9. Dani, F.R.; Michelucci, E.; Francese, S.; Mastrobuoni, G.; Cappellozza, S.; Marca, G.L.; Niccolini, A.; Felicioli, A.; Moneti, G. Odorant-Binding Proteins and Chemosensory Proteins in Pheromone Detection and Release in the Silkmoth Bombyx mori. Chem. Senses 2011, 36, 335-344. [CrossRef]

10. Ban, L.; Scaloni, A.; Brandazza, S.; Angeli, Z. Chemosensory proteins of Locusta migratoria. Insect Mol. Biol. 2003, 12, 125-134. [CrossRef] [PubMed]

11. Vogt, R.G. Biochemical diversity of odor detection: OBPs, ODEs and SNMPs-ScienceDirect. Insect Biochem. Mol. 2003, 391-445.

12. Nichols, Z.; Vogt, R.G. The SNMP/CD36 gene family in Diptera, Hymenoptera and Coleoptera: Drosophila melanogaster, D. pseudoobscura, Anopheles gambiae, Aedes aegypti, Apis mellifera, and Tribolium castaneum. Insect Biochem. Mol. 2008, 38, 398-415. [CrossRef] [PubMed]

13. Hallem, E.A.; Dahanukar, A.; Carlson, J.R. Insect odor and taste receptors. Annu. Rev. Entomol. 2006, 51, 113-135. [CrossRef]

14. Elmore, T.; Smith, D.P. Putative Drosophila odor receptor OR43b localizes to dendrites of olfactory neurons. Insect Biochem. Mol. 2001, 31, 791-798. [CrossRef]

15. Mabèche-Coisne, M.; Merlin, C.; Rosell, G.; Carot, G.; Jacquin-Joly, E. Odorant-degrading enzymes of moths. In Proceedings of the 22th International Society of Chemical Ecology, Barcelona, Spain, 15-19 July 2006.

16. Steiner, C.; Bozzolan, F.; Montagné, N.; Maibèche, M.; Chertemps, T. Neofunctionalization of "Juvenile Hormone Esterase Duplication" in Drosophila as an odorant-degrading enzyme towards food odorants. Sci. Rep. 2017, 7, 12629. [CrossRef] [PubMed]

17. Ahmad, S.A.; Hopkins, T.L. $\beta$-Glucosylation of plant phenolics by phenol b-glucosyltransferase in larval tissues of the tobacco hornworm, Manduca sexta (L.). Insect Biochem. Mol. 1993, 23, 581-589. [CrossRef]

18. Luque, T.; O'Reilly, D.R. Functional and phylogenetic analyses of a putative Drosophila melanogaster UDP-glycosyltransferase gene. Insect Biochem. Mol. 2002, 32, 1597-1604. [CrossRef]

19. Ahmad, S.A.; Hopkins, T.L. Phenol $\beta$-glucosyltransferases in six species of insects: Properties and tissue localization. Comp. Biochem. Phys. B 1993, 104, 515-519. [CrossRef]

20. Heydel, J.M.; Holsztynska, E.J.; Legendre, A.; Thiebaud, N.; Artur, Y.; Bon, A. UDP-glucuronosyltransferases (UGTs) in neuroolfactory tissues: Expression, regulation, and function. Drug Metab. Rev. 2010, 42, 74-97. [CrossRef]

21. Tephly, T.R.; Burchell, B. UDP-glucuronosyltransferases: A family of detoxifying enzymes. Trends Pharmacol. Sci. 1990, 11, 276-279. [CrossRef]

22. Bozzolan, F.; Siaussat, D.; Maria, A.; Durand, N.; Maibèche-Coisne, M. Antennal uridine diphosphate (UDP)-glycosyltransferases in a pest insect: Diversity and putative function in odorant and xenobiotics clearance. Insect Mol. Biol. 2015, 23, 539-549. [CrossRef] [PubMed]

23. Huang, F.F.; Chai, C.L.; Zhang, Z.; Liu, Z.H.; Dai, F.Y.; Lu, C.; Xiang, Z.H. The UDP-glucosyltransferase multigene family in Bombyx mori. BMC Genom. 2008, 9, 563. [CrossRef] [PubMed]

24. Brierley, C.H.; Burchell, B. Human UDP-glucuronosyl transferases: Chemical defence, jaundice and gene therapy. Bioessays 1993, 15, 749-754. [CrossRef] [PubMed]

25. Zhang, J.h.; Pelletier, Y.; Goyer, C. Identification of potential detoxification enzyme genes in Leptinotarsa decemlineata (Say) and study of their expression in insects reared on different plants. Can. J. Plant Sci. 2008, 88, 621-629. [CrossRef]

26. Wang, Y.H.; Gu, Z.Y.; Wang, J.M.; Sun, S.S.; Wang, B.B.; Jin, Y.Q.; Shen, W.D.; Li, B. Changes in the activity and the expression of detoxification enzymes in silkworms (Bombyx mori) after phoxim feeding. Pestic. Biochem. Phys. 2013, 105, 13-17. [CrossRef]

27. Bull, D.L.; Whitten, C.J. Factors influencing organophosphorus insecticide resistance in tobacco budworms. J. Agric. Food Chem. 1972, 20, 561. [CrossRef]

28. Rane, R.V.; Walsh, T.K.; Pearce, S.L.; Jermiin, L.S.; Oakeshott, J.G. Are feeding preferences and insecticide resistance associated with the size of detoxifying enzyme families in insect herbivores? Curr. Opin. Insect Sci. 2016, 13, 70-76. [CrossRef]

29. Rane, R.V.; Ghodke, A.B.; Hoffmann, A.A.; Edwards, O.R.; Walsh, T.K.; Oakeshott, J.G. Detoxifying enzyme complements and host use phenotypes in 160 insect species. Curr. Opin. Insect Sci. 2019, 31, 131-138. [CrossRef]

30. Sudhir, K.; Glen, S.; Koichiro, T. MEGA7: Molecular Evolutionary Genetics Analysis Version 7.0 for Bigger Datasets. Mol. Biol. Evol. 2016, 33, 1870-1874.

31. Livak, K.J.; Schmittgen, T. Analysis of relative gene expression data using real-time quantitative PCR and the 2-DDCt method. Methods 2001, 25, 402-408. [CrossRef]

32. Li, L.C.; Okino, S.T.; Zhao, H.; Pookot, D.; Place, R.F.; Urakami, S.; Enokida, H.; DahiyaSmall, R. dsRNAs induce transcriptional activation in human cells. Proc. Natl. Acad. Sci. USA 2006, 103, 17337-17342. [CrossRef] [PubMed]

33. Bhumika, B.; Kumar, S.A. Regulation of feeding behavior in Drosophila through the interplay of gustation, physiology and neuromodulation. Front. Biosci. 2018, 23, 2016-2027. 
34. Ahn, S.J.; Badenes-Pérez, F.; Reichelt, M.; Svato, A.; Schneider, B.; Gershenzon, J.; Heckel, D.G. Metabolic detoxification of capsaicin by UDP-glycosyltransferase in three Helicoverpa species. Arch. Insect Biochem. 2011, 78, 104-118. [CrossRef] [PubMed]

35. Ahn, S.J.; Vogel, H.; Heckel, D.G. Comparative analysis of the UDP-glycosyltransferase multigene family in insects. Insect Biochem. Mol. Biol. 2012, 42, 133-147. [CrossRef] [PubMed]

36. Tian, L.; Gao, X.; Zhang, S.; Zhang, Y.; Ma, D.; Cui, J. Dynamic changes of transcriptome of fifth-instar spodoptera litura larvae in response to insecticide. 3 Biotech 2021, 11,98. [CrossRef]

37. Li, J.; Moghaddam, S.; Chen, X.; Chen, M.; Zhong, B. Shotgun strategy-based proteome profiling analysis on the head of silkworm Bombyx mori. Amino Acids 2010, 39, 751-761. [CrossRef]

38. Li, Y.; Wang, X.; Chen, Q.; Hou, Y.; Xia, Q.; Ping, Z. Metabolomics Analysis of the Larval Head of the Silkworm, Bombyx mori. Int. J. Mol. Sci. 2016, 17, 1460. [CrossRef] [PubMed]

39. Bosquet, G. Nutritional and non nutritional stimulations of protein synthesis in the fat body of Bombyx mori. Insect Biochem. 1983, 13, 281-288. [CrossRef]

40. Tojo, S.; Kiguchi, K.; Kimura, S. Hormonal control of storage protein synthesis and uptake by the fat body in the silkworm, Bombyx mori. J. Insect Physiol. 1981, 27, 491-497. [CrossRef]

41. Bosquet, G. Occurrence of an active regulatory mechanism of protein synthesis during starvation and refeeding in Bombyx mori fat body. Biochimie 1979, 61, 165-170. [CrossRef]

42. Nath, B.S.; Suresh, A.; Varma, B.M.; Kumar, R.P. Changes in protein metabolism in hemolymph and fat body of the silkworm, Bombyx mori (Lepidoptera: Bombycidae) in response to organophosphorus insecticides toxicity. Ecotoxicol. Environ. Saf. 1997, 74, 73-84. [CrossRef] [PubMed]

43. Schneider, D. 100 years of pheromone research. Naturwissenschaften 1992, 79, 241-250. [CrossRef]

44. Pansopha, P.; Ando, N.; Kanzaki, R. Dynamic use of optic flow during pheromone tracking by the male silkmoth, Bombyx mori. J. Exp. Biol. 2014, 217, 1811-1820. [CrossRef] [PubMed]

45. Lazard, D.; Zupko, K.; Poria, Y.; Net, P.; Lazarovits, J.; Horn, S.; Khen, M.; Lancet, D. Odorant signal termination by olfactory UDP glucuronosyl transferase. Nature 1991, 349, 790-793. [CrossRef] [PubMed]

46. Eubanks, M.D.; Styrsky, J.D.; Denno, R.F. The evolution of omnivory in heteropteran insects. Ecology 2003, 84, 2521. [CrossRef]

47. Tanaka, K.; Uda, Y.; Ono, Y.; Nakagawa, T.; Suwa, M.; Yamaoka, R.; Touhara, K. Highly Selective Tuning of a Silkworm Olfactory Receptor to a Key Mulberry Leaf Volatile. Curr. Biol. 2009, 19, 881-890. [CrossRef]

48. Zhang, Z.J.; Zhang, S.S.; Niu, B.L.; Ji, D.F.; Liu, X.J.; Li, M.W.; Bai, H.; Palli, S.R.; Wang, C.Z.; Tan, A.J. A determining factor for insect feeding preference in the silkworm, Bombyx mori. PLoS Biol. 2019, 17, e3000162. [CrossRef] [PubMed]

49. Mang, D.; Shu, M.; Endo, H.; Yoshizawa, Y.; Nagata, S.; Kikuta, S.; Sato, R. Expression of a sugar clade gustatory receptor, bmgr6, in the oral sensory organs, midgut, and central nervous system of larvae of the silkworm bombyx mori. Insect Biochem. Mol. 2016, 70, 85-98. [CrossRef]

50. Bock, H.E.; Hartl, W.; Genth, E. In vitro binding of complement on leukocytes. contribution to the immunopathogenesis of schultz's drug allergic agranulocytosis. Schweiz. Med. Wochr. 1970, 100, 617-622.

51. Zhang, S.X. Expression of general odorant binding proteins in silkworm bombyx mori and molecular evaluation in lepidoteran insects. Sci. Seric. 2010, 36, 610-618.

52. Forstner, M.; Gohl, T.; Breer, H.; Krieger, J. Candidate pheromone binding proteins of the silkmoth bombyx mori. Invertebr. Neurosci. 2006, 6, 177-187. [CrossRef] [PubMed]

53. Wanner, K.W.; Anderson, A.R.; Trowell, S.C.; Theilmann, D.A.; Robertson, H.M.; Newcomb, R.D. Female-biased expression of odourant receptor genes in the adult antennae of the silkworm, bombyx mori. Insect Mol. Biol. 2007, 16, 107-119. [CrossRef] [PubMed] 